\title{
The Use of Gore-tex Vascular Grafts in Microvascular Decompression for Patients with Hemifacial Spasm
}

\author{
- Technical Note-
}

\author{
Totaro TAKEUCHI and Eishi KASAHARA \\ Neurosurgical Department, The Municipal Higashimatsuyama Hospital, \\ Higashimatsuyama, Saitama
}

\begin{abstract}
Microvascular decompression was performed in 10 hemifacial spasm patients using Gore-tex vascular grafts as a prosthesis. Postoperative complication (transient deafness) occurred only in one patient, and recurrence in none during follow-up of $1-51$ months, indicating that Gore-tex is a very effective prosthesis.
\end{abstract}

Key words: microvascular decompression, facial spasm, Gore-tex, vascular graft

\section{Introduction}

Microvascular decompression (MVD) can achieve satisfactory results in the treatment of hemifacial spasm and trigeminal neuralgia, ${ }^{1,3,46.7,9)}$ but some cases demonstrate no response or recurrence. ${ }^{5,7,9)}$ In this study, we analyzed the operative results of MVD performed mainly in hemifacial spasm patients using Gore-tex vascular grafts as a prosthesis.

\section{Patients and Results}

MVD was performed on 10 hemifacial spasm patients (left 5 , right 5 ) with no evidence of organic lesions or response to drug medication, aged between 29 and 73 years (mean, $44.5 \mathrm{yrs}$ ), according to the method of Jannetta ${ }^{3-5)}$ (Table 1). The compressing vessel was the meatal branch of the anterior inferior cerebellar artery (AICA) (4 cases), the main trunk of the AICA (3), the cerebellar branch of the AICA (1), and branches of the posterior inferior cerebellar artery (2). Gore-tex (W.L. Gore \& Associates, Inc., Eikton, Md., U.S.A.) vascular grafts of $8 \mathrm{~mm}$ diameter were used as the prosthesis for decompression (Fig. 1). Gore-tex was cut in round slices of $1-3 \mathrm{~mm}$ thickness according to the individual requirements. One Gore-tex slice was usually sufficient, but two slices were used if necessary.

Received April 1, 1992; Accepted July 6, 1992
Table 1 Patients treated with Gore-tex vascular graft for hemifacial spasm

\begin{tabular}{rlrcrl}
\hline $\begin{array}{c}\text { Case } \\
\text { No. }\end{array}$ & $\begin{array}{c}\text { Age, } \\
\text { Sex }\end{array}$ & Side & $\begin{array}{c}\text { Follow-up } \\
\text { period } \\
\text { (mos) }\end{array}$ & $\begin{array}{c}\text { Recur- } \\
\text { rence }\end{array}$ & Complication \\
\hline 1 & $54, \mathrm{M}$ & $\mathrm{rt}$ & 19 & none & \\
2 & $42, \mathrm{~F}$ & It & 51 & none & \\
3 & $29, \mathrm{~F}$ & It & 5 & none & \\
4 & $56, \mathrm{M}$ & It & 9 & none & \\
5 & $34, \mathrm{~F}$ & rt & 26 & none & \\
6 & $73, \mathrm{M}$ & It & 13 & none & hearing loss \\
7 & $39, \mathrm{~F}$ & rt & 1 & none & \\
8 & $45, \mathrm{~F}$ & rt & 3 & none & \\
9 & $32, \mathrm{M}$ & It & 32 & none & \\
10 & $41, \mathrm{~F}$ & rt & 11 & none & \\
\hline
\end{tabular}

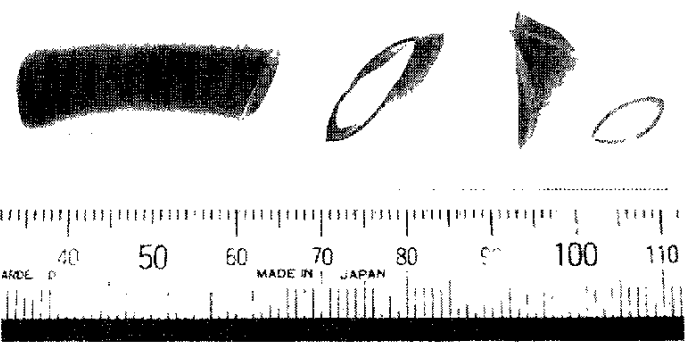

Fig. 1 Gore-tex vascular graft for MVD. 


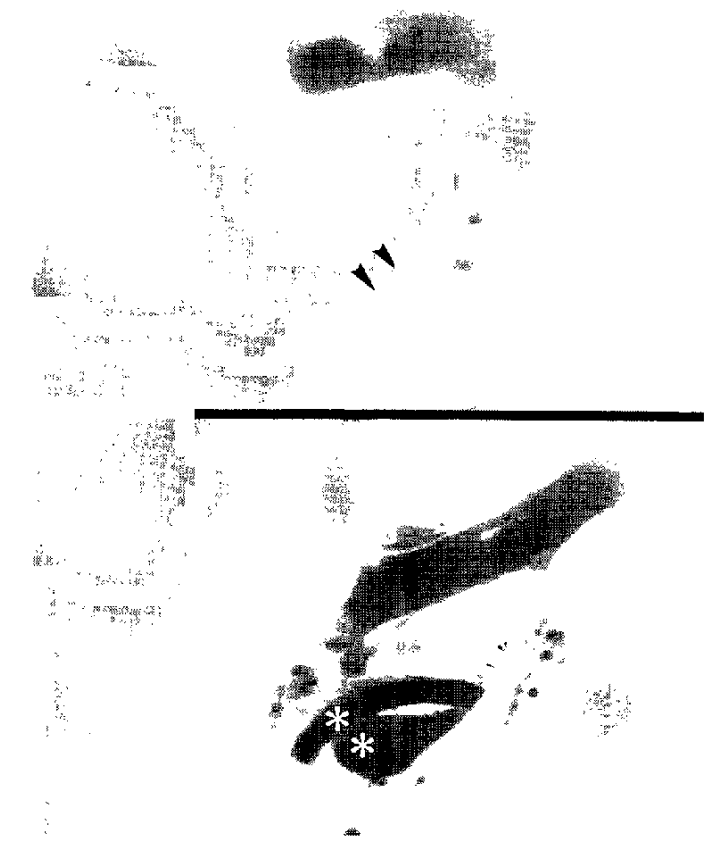

Fig. 2 Case 1. Compressing vessel is the main trunk of the AICA (arrowheads) which is decompressed by two Gore-tex pieces (asterisks). upper: pre-decompression, lower: post-decompression.

The patients were observed to detect postoperative complications and recurrence during 1-51 months. Transient homolateral deafness occurred in one patient, but spontaneously remitted in 1 week. No recurrence was observed during the follow-up period.

Representative cases: Case 1 was a 54-year-old male with initial symptoms of spasm in the lower eyelid. The main trunk of the AICA compressed the facial nerve. MVD required two Gore-tex slices of $1 \mathrm{~mm}$ width (Fig. 2). Case 2 was a 42 -year-old female also suffering spasm in the lower eyelid. The compressing vessel was the meatal segment of the AICA. MVD was accomplished with one Gore-tex slice of $2 \mathrm{~mm}$ width (Fig. 3).

\section{Discussion}

There are many MVD methods, such as the vessel fixation method where the compressing vessel is wrapped in a small Dacron ${ }^{\circledR}$ (E.I. Dupont De Nemours \& Co., Wilmington, Del., U.S.A.) sling and then sutured on the dura mater, ${ }^{13}$ and the nerve-coating method where the compressed nerve is protected by wrapping in a clip. ${ }^{8)}$ The most widely
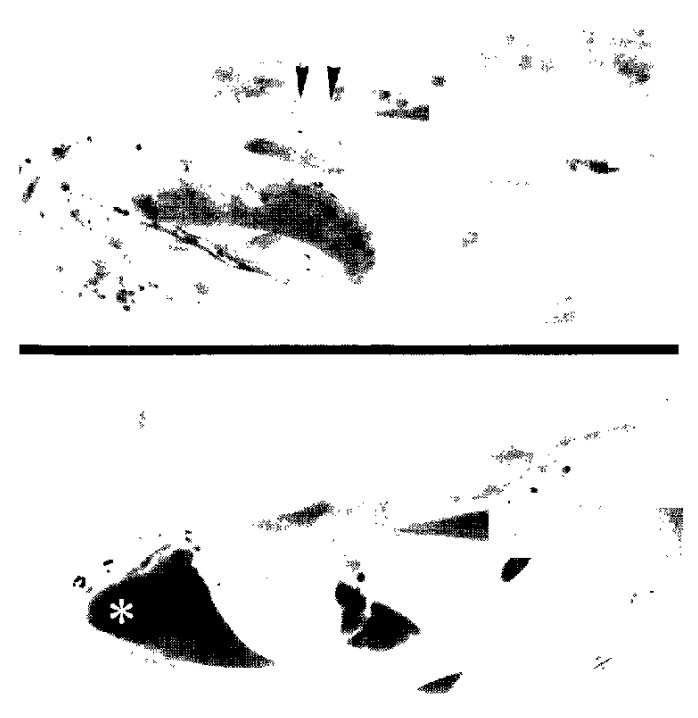

Fig. 3 Case 2. Compressing vessel is the meatal segment of the AICA (arrowheads) which is decompressed by one Gore-tex piece (asterisk). upper: pre-decompression, lower: post-decompression.

used method inserts a prosthesis to prevent the compressing vessel touching the root entry zone of the nerve. In the early days, a prosthesis was directly inserted between the nerve and vessel (direct packing method). However, the most important technical point in MVD is to mobilize and transpose all offending vessels and to fix the vessel in the repositioned location. Therefore, the prosthesis has been inserted so the nerve is entirely isolated from any contact (indirect packing method) in recent years (Fig. 4).

There are many prosthesis materials in current use, such as autogenous muscle, ${ }^{2)}$ vinyl sponge, ${ }^{6)}$ and Ivalon sponge. ${ }^{3)}$ However, patients not responding to MVD using these materials have been reported in $1.8-19 \%$ of cases, ${ }^{5,7,9)}$ and recurrences due to displacement of the prosthesis in $3.1 \%$ of cases. ${ }^{5} \mathrm{We}$ previously performed MVD using vinyl sponge as the prosthesis in 25 patients. However, two cases recurred probably because the vinyl sponge moved, leading to direct packing, and also hardening due to histological reaction.

Gore-tex vascular grafts are made of porous polytetrafloroethylene and mainly used in thoracic vascular surgery. Biocompatibility (little reaction to 
Direct packing method

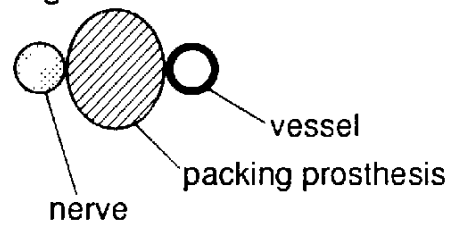

Vessel fixation method

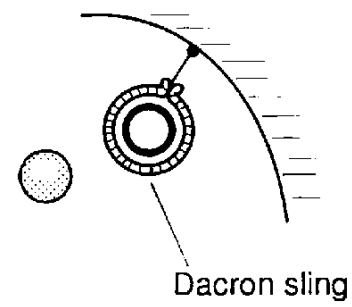

Nerve-coating method

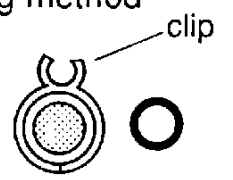

Indirect packing method

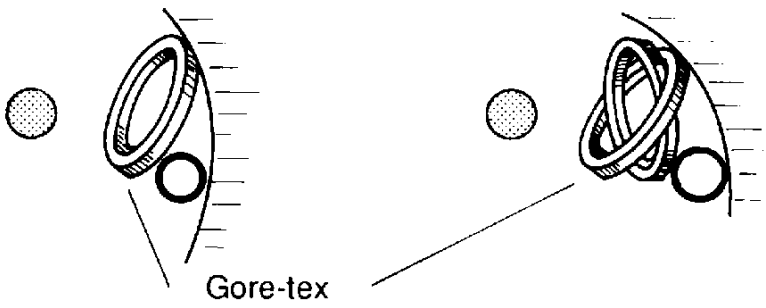

Fig. 4 MVD methods.

a foreign body), toughness (high elasticity), hydrophobicity, and stability to displacement are characteristics of Gore-tex. When used as a prosthesis, Gore-tex of $8 \mathrm{~mm}$ diameter is cut in round slices of 1-3 $\mathrm{mm}$ width according to the individual requirements. The prosthesis is inserted between the compressing vessel and the external aspect of the brainstem to isolate the nerve. Although we usually use one slice, another is added when the compressing vessel has severe arteriosclerosis or short perforating branches, or insufficient decompression is achieved. Up to date, we have encountered only one case of postoperative complication, and no postoperative recurrences.

We consider Gore-tex the best prosthesis for MVD as manipulation is simple, the space between the blood vessel and nerve can be adjusted due to the elasticity, the length to be separated is adjustable, and stability to displacement is good.

\section{References}

1) Fukushima T: Posterior fossa microvascular decompression in the management of hemifacial spasm and trigeminal neuralgia. No Shinkei Geka 10: 12571261, 1982 (in Japanese)

2) Jannetta PJ: Microsurgical exploration and decompression of the facial nerve in hemifacial spasm. Curr Top Surg Res 2: 217-220, 1970

3) Jannetta PJ: Hemifacial spasm, in Samei M, Jannetta PJ (eds): The Cranial Nerves: Anatomy, Pathology, Pathophysiology, Diagnosis and Treatment. New York, Springer \& Verlag, 1981, pp 484493

4) Jannetta PJ: Hemifacial spasm, in Scheingerg P (ed): Neurology and Neurosurgery Update Series, vol 3. Princeton, NJ, Continuing Professional Educational Center, 1982, pp 1-7

5) Jannetta PJ, Abbasy M, Maroon JC, Ramos FM, Albin MS: Etiology and definitive microsurgical treatment of hemifacial spasm. Operative techniques and results in 47 patients. $J$ Neurosurg 47: 321-328, 1977

6) Kondo A, Ishikawa J, Hiwatari S: Surgical results of the treatment of hemifacial spasm, tinnitus and trigeminal neuralgia by the method of "microvascular decompression." No Shinkei Geka 7: 677682, 1979 (in Japanese)

7) Kondo A, Ishikawa J, Ito $K$, Niijima $K$, Kim C, Konishi T: Hemifacial spasm: Its mechanism and operative results by a microvascular decompression for the facial nerve. Neurosurgeons 2: 239-249, 1983 (in Japanese)

8) Laws ER Jr, Kerry PJ, Sundt TM Jr: Clip-grafts in microvascular decompression of the posterior fossa. Technical note. $J$ Neurosurg 64: 679-681, 1986

9) Tsubokawa $T$, Katayama $Y$ : Hemifacial spasm, in Abe H, Kikuchi H, Tanaka R, Tsubokawa $T$, Hirakawa $\mathrm{K}$, Matsumoto $\mathrm{S}(\mathrm{eds})$ : Operation and Indication of Neurosurgical Disease I. Tokyo, Asakura, 1990, pp 509-520 (in Japanese)

Address reprint requests to: T. Takeuchi, M.D., Neurosurgical Department, The Municipal Higashimatsuyama Hospital, 2392 Matsuyama, Higashimatsuyama, Saitama 355, Japan. 